\title{
O 'VOZEAR' NA MATA E A MODERNIDADE ANUNCIADA: EDUCAÇÃO NO TERRITÓRIO DO ACRE ATRAVÉS DOS JORNAIS (1906-1930)
}

\author{
Andréa Maria Lopes Dantas \\ Universidade Federal do Acre - UFAC
}

\section{RESUMO}

Este ensaio tem por objetivo determinar o lugar ocupado pelo impresso no processo de organização dos serviços de educação escolar no território do Acre no período de 19061930. O Jornal desempenha, no período que a análise recobre, importante papel no processo de organização dos serviços de educação no Território do Acre ao se constituir como um orientador dos procedimentos administrativos que eram adotados pelo governo como e, principalmente como um arauto do 'novo modelo de educação' que se estava a praticar país afora, especialmente se considerado que este funciona como uma espécie de 'diário oficial' das administrações locais. Admitido que este é um elemento que está presente nos materiais analisados é possível considerar que, ao manter a publicação de matérias que expressam a direção política e as determinações que o Governo Federal está a anunciar para os serviços públicos, o jornal garante um espaço imprescindível para que estas matérias tenham o impacto necessário em seus leitores. As falas provenientes do Governo encontram assim o espaço necessário para serem lidas como a anunciação do novo, abrindo a possibilidade de que o Território se integre ao desenvolvimento que o País vivencia no que tange a educação, organização administrativa e política

Palavras-chave: Jornal, educação acreana, história da educação

\section{THE 'SOUND PRODUCED' IN THE FOREST AND THE MODERNITY ANNOUNCED: EDUCATION IN THE TERRITORY OF ACRE THROUGH THE NEWSPAPERS (1906-1930)}

\begin{abstract}
This essay aims at determining the role played by the press in the process of organization of school education services in the territory of Acre, Brazil, in the period from 1906 to 1930. The newspapers - in the selected period - have a strong import in the education services organization process in Acre due to the fact that they function as a reference for the administrative procedures adopted by the government, as well as a herald for the 'new model of education' being implemented in the other parts of the country, for they acted as a kind of 'daily official chronicle' for local administrations. Being admitted that those functions can be detected in the corpus analyzed, it is possible to infer that, on k eeping the publication of texts which convey the government policy and directions for public services, the newspapers guarantee an indispensable space to forge the intended impact on the readers. The government discourse finds the necessary vehicle to announce it as the representation of a new era which opens possibilities for the territory to participate in the ongoing development being experienced in the fields of education, administration and politics.
\end{abstract}

Keywords: Newspapers, education in Acre, history of education 
No momento em que me foi solicitada a organização de um texto no qual elementos relativos a História da Educação na Amazônia foram inúmeras possibilidades que se apresentariam. Realizar uma análise sobre o modo como a disciplina história da educação foi trabalhada no curso de pedagogia no período de implantação do ensino superior no Acre? Analisar os códigos de educação produzidos no governo territorial, ou seria mais interessante trabalhar com o discurso produzido pelos chamados autonomistas ${ }^{1}$, na defesa da elevação do território do Acre a categoria de Estado e o papel da educação nesse processo?

Mesmo diante de tantos caminhos um elemento unia a todos e abria uma possibilidade de agregar os estudos já realizados com as pesquisas mais recentes, qual seja o uso do impresso como o suporte em que se punham a circular, matérias, notas técnicas, comunicados, atos oficiais e notícias do país e do exterior, dentre outras, com o propósito de difundir um projeto de educação escolar, contribuir na organização dos serviços de educação no território acreano ou ainda na definição de princípios que normatizariam procedimentos e condutas que modelariam a sociedade, como no caso dos autonomistas.

Mesclam-se aqui a busca pela formação de uma 'mentalidade em matéria de educação' e a eficiente propaganda dos governantes do território do Acre na divulgação das ações praticadas e pretendidas no campo educacional, sempre perspectivada pela modernidade requerida e anunciada.

No período compreendido entre 1904 a 1946, foram publicados mais 30 jornais no território acreano com periodicidade que variam entre dois e dez anos. São folhas literárias, jornais que criticam a ação dos governos locais, jornais oficiais, jornais particulares com uma periodicidade média de dois anos, dentre estes últimos, alguns são editados por famílias influentes que admitem o impresso como um importante mecanismo de divulgação de sua posição quanto a política local ${ }^{2}$.

Para efeito da análise aqui realizada foram selecionados os jornais publicados pelos Departamentos Administrativos ${ }^{3}$ do Território do Acre e pelo governo Territorial, respectivamente Acre, $O$ Alto Purus e $O$ Cruzeiro do $\mathrm{Sul}^{4}$. A seleção do material está posta na indicação de que estes se constituam em órgãos oficiais de divulgação das ações do governo departamental e territorial, o que pode ser determinado a partir da declaração posta no expediente do jornal Alto Purus em 1908, declaração esta que se repetem nos demais jornais, quando se informa aos leitores que este será

(...) usado para a publicação dos atos emanados dos governos federal e do Departamento, que se relacionem com os interesses gerais da República e que de perto afetem os interesses particulares da prefeitura do alto Purus. (cf. Departamento do Alto Purus, O Alto Purus, 24 de fevereiro de 1908),

Apesar da declaração expressa de que se constituíam em uma espécie de 'diário oficial' do governo departamental, os jornais não se restringiam a publicações de atos oficiais e notícias que davam conta de procedimentos administrativos e políticas que o governo federal e territorial estava a admitir para o território acreano.

Um caso exemplar são as notações publicadas no jornal Alto Purus ${ }^{5}$, na declaração explicita das finalidades deste como um órgão destinado a publicar em primeiro lugar os atos e fatos relativos a Prefeitura do Departamento do Alto Purus. Por ocasião da edição de seu primeiro número, é informado aos leitores que o periódico,

"É um jornal usado para a publicação dos atos emanados dos governos federal e do Departamento, que se relacionem com os interesses gerais da República e que de perto afetem os interesses particulares da Prefeitura 
do Alto Purus. Excluirá em absoluto de suas colunas quaisquer publicações irritantes de polemicas, o que importa na exclusão completa do anonimato, sob qualquer aspecto que o mesmo se apresente". (ALTO PURUS, 24 de fevereiro de 1908)

Ao mesmo tempo, o editor demarca o afastamento deste semanário de questões políticas e partidárias e declara:

Orgam official como é, o Alto Purus é absolutamente alheio à política e a questões partidárias, tem por fim exclusivo contribuir com o concurso inherentes às suas forças para o engrandecimento des longínquo e ainda ignorado canto da futura Nação Brazileira (...). (ALTO PURUS, 24 de fevereiro de 1908, grifo nosso).

Ao comemorar o terceiro ano de publicação a pretendida 'neutralidade' é reiterada e, mais uma vez os leitores são informados do propósito do jornal:

"O nosso aniversário"

Visando sempre a causa geral da colectividade, jornais em suas colunnas se feriram polemicas ou se agitaram questões, por onde pudessem enxergar laivos de politicas, oppondo o seu programa um interesse outro, que não o da mais absoluta comprehensão de seus fins.

Leal ao dever que lhe deu e imposição que cerca todos os jornaes do governo, tem mantido sempre até hoje a mais meticulosa severidade de opinião, não intervindo em questões que effectem interesses partidários ou espoiricto de facções. (ALTO PURUS, 25 de fevereiro de 1911, grifo nosso).

Considerando que o Jornal declara-se firmemente comprometido com o desenvolvimento do País e que as nomeações para o cargo de Prefeito do Departamento são feitas pelo Presidente da República é possível considerar, apesar de não estar formalmente declarado que a posição defendida pelo Jornal é a Republicana, ainda que este não se constitua em porta-voz do partido republicano.

Além da seção denominada Actos Officiais, comum a todos os jornais analisados, a pesquisa determinou a existência de seções que dão conta da vida social dos habitantes locais, uma seção que publica pequenas resenhas de livros e revistas recebidas pela Prefeitura, o boletim da associação comercial local, os acontecimentos policiais. Na seção denominada notícias é possível verificar a divulgação de matérias publicadas em jornais de circulação nacional e em jornais que circulam nos Departamentos Territoriais. Os reclames ocupam um espaço considerável nos jornais e não se restringem as divulgações relativas a casas comerciais, muitas são as publicações em que médicos, advogados e professores oferecem seu trabalho a comunidade local.

O consórcio entre as notícias provenientes das repartições públicas e de particulares, nas edições dos jornais 'oficiais', se mantém ao longo dos anos. A hipótese para tal organização é a de que não seria possível ao poder público manter a periodicidade dos jornais com o subsídio dos Departamentos Territoriais. Alia-se a essa consideração o fato da probabilidade de não existirem matérias suficientes para garantir a periodicidade dos jornais, se consideradas apenas as matérias e notícias oriundas do poder público.

Importa salientar que, apesar destes jornais se constituírem em órgãos oficiais do poder público os mesmos não são distribuídos gratuitamente e a publicação de matérias e notícias obedece a critérios bem definidos e anunciados a todos os leitores. Essa orientação 
é publicada no expediente do jornal O Cruzeiro do Sul, determinando que as notícias oriundas das repartições públicas só seriam publicadas se devidamente acompanhada

de requisições e assinadas pelos respectivos chefes declarando o número de vezes que devem ser publicados' e os serviços de impressões, e publicações particulares, só serão executados depois de previamente pagos na Contadoria da Prefeitura. (Cf. Departamento do Alto Juruá, O Cruzeiro do Sul, n. 449 de 24/10/1915).

No expediente do jornal $O$ Acre, do ano de 1935 fica indicado que este é vendido de forma avulsa e por assinatura, esta se dando por semestre ou anualmente. As assinaturas têm valor distinto para particulares e para funcionários públicos, sendo a destes últimos $1 / 3$ mais barata. Também está determinado que o pagamento das matérias se darão 'adiantadamente e aquelas que excederem 50 linhas, o pagamento será feito mediante um valor 'a combinar' Ainda que sejam pagas as matérias são autorizadas, sempre, mediante o visto do secretário geral.

As matérias e notícias relativas ao poder público, no jornal $O$ Acre ${ }^{6}$ dividem-se nas seguintes seções: expediente da Interventoria, espaço em que são publicados telegramas expedidos e recebidos, Diretoria de Educação Estatística e Biblioteca, espaço destinado a publicação de atos relativos a nomeação e exoneração de professores, locação de estabelecimentos de ensino, remessa de mapas e relatórios estatísticos, movimento escolar; Diretoria de Obras, Agricultura e Trabalho, Diretoria de Higiene e saúde Pública e Chefatura de Polícia; Atos do Governo federal, Diretoria de Contabilidade e Tesouraria, Aumoxarifado Geral do Governo, Força Policial do Território do Acre.

Agregam-se a essas seções a dedicada as notícias sobre os habitantes locais, tanto na forma de uma espécie de 'coluna social', na notificação dos aniversários, viagem, chegadas e partidas de figuras da sociedade acreana, além de matérias pagas que, tratam de questões gerais e relativas a vida citadina.

No ano de 1920, com a publicação do Decreto Presidencial n. 14.383 em 1 de outubro de 1920 o território do Acre passa da estrutura departamental para o regime unificado territorial, permanecendo nessa condição até 1962, quando passa a condição de estado federado ${ }^{7}$. No processo da unificação territorial, os jornais analisados sofrem modificações na sua estrutura material e no processo de edição, alguns chegando até a desaparecer $^{8}$, especialmente porque não fazia mais sentido um periódico que retratasse as questões dos Departamentos. ${ }^{9}$

No ano de 1925, o Governador do Território do Acre, Dr. José Thomaz da Cunha Vasconcelos apresenta ao Ministro da Justiça e Negócios Interiores o Relatório de seu governo. Nesse texto, no item 'imprensa oficial' fica explicitado a necessidade de dar publicidade a ação administrativa. De acordo com o Cunha Vasconcelos,

Possuindo o governo grande copya de material typografico, arrecadado às
extintas prefeituras, e como precisasse e fosse conveniente dar a maior
publicidade possível aos atos da administração (...) cedi a título precário a
Intendência desta capital para que ela os arrendasse a pessoa competente,
que quizesse encarregar-se de publicação dos actos do governo territorial
e das cinco municipalidades aqui existente. (cf. Relatório Cunha
Vasconcelos, 1925 - Museu da Borracha)

A cessão do maquinário 'a pessoa competente' garante ao poder público a publicação dos atos e fatos oficiais, sem que se tenha que operar com os dispêndios decorrentes da manutenção de um periódico que dê visibilidade a ação governamental. 
A partir desse momento o jornal $O$ Acre, antes órgão oficial do Departamento do Alto Acre, se institui como semanário oficial do governo do Território do Acre e passa a divulgar com maior intensidade matérias relativas aos protocolos administrativos do governo territorial. Inicia-se um período de absoluta fertilidade de matérias que orientam, dirigem e indicam quais os melhores procedimentos que o professorado deveria adotar no desenvolvimento das ações de educação, todas elas oriundas do Departamento de Educação e Cultura ${ }^{10}$ e do Departamento de Geografia e Estatística, este último funcionava como órgão regional com ligações com o Serviço de Estatística do Ministério da Educação e Saúde Pública.

Importa aqui considerar que, ao garantir que um semanário destinado à publicação dos atos oficiais oriundos do poder público também faça circular informações relativas a sociedade local e os acontecimentos nacionais, os editores dos jornais garantem, de forma bastante astuciosa a leitura dos atos oficiais.

O traço distintivo do material analisado está posto na forma como as ações governamentais são divulgadas. Aparentemente não há nenhuma edição nos textos publicados, no sentido de impedir que os leitores tenham acesso a informações que seriam de domínio exclusivamente administrativo.

O traço que os editores dos jornais dão a perceber é que a seção atos oficiais dedica-se apenas a registrar as ações da administração departamental. Assim é que os leitores dos jornais dos Departamentos Territoriais acompanham a movimentação, criação e fechamento de escolas, a adoção de métodos para a instrução pública, contratação e exoneração de professores, cotação da borracha, as novidades políticas e comerciais, assim como os relatórios dos chefes dos Departamentos, telegramas recebidos e expedidos ao poder público federal, dentre outras informações.

É possível considerar que ao dar início ao processo de formação administrativa do Território do Acre é importante partilhar informações, reforçar procedimentos e, mais do que isso, estabelecer uma comunidade de leitores que acompanhem e chancelem as ações do poder político local, mantendo como perspectiva a defesa do Território e a inserção deste nas discussões nacionais a propósito de temas ligados a modernização dos serviços administrativos, da instrução, do comércio e da saúde pública ao mesmo tempo em que acompanham, nas páginas dos jornais, as notícias relativas ao cotidiano local e aos acontecimentos nacionais e internacionais.

Admitido que este é um elemento que está presente nos materiais analisados é possível considerar como hipótese que, ao manter a publicação de matérias que expressam a direção política e as determinações que o Governo Federal está a anunciar para os serviços públicos, o jornal garante um espaço imprescindível para que estas matérias tenham o impacto necessário em seus leitores sem que sejam questionadas as ordenações procedentes do poder público federal ou territorial. As falas provenientes do Governo encontram assim o espaço necessário para serem lidas como a anunciação do novo, da possibilidade de que o Território se integre ao desenvolvimento que o País vivencia no que tange a educação, organização administrativa e política.

Agregam-se a essas questões a possibilidade de perceber, a partir da leitura de um periódico, como que redes de saberes se constituem e como esse periódico conforma determinados comportamentos em seus leitores constituindo práticas culturais. Nesse sentido, as formulações de Chartier $(1990)^{11}$ passam a ser utilizadas na perspectiva de admitir que aquilo que é dado a ler é crivado por representações sociais e que,

As percepções do social não são de forma alguma discursos neutros: produzem estratégias e práticas (sociais, escolares, políticas) que tendem 
a impor uma autoridade a custa de outros, por elas menosprezados, a legitimar um projeto reformador ou a justificar, para os próprios indivíduos, as suas escolhas e condutas. (...) As lutas de representações têm tanta importância como as lutas econômicas para compreender os mecanismos pelos quais um grupo impõe, ou tenta impor, a sua concepção de mundo social, os valores que são os seus, e o seu domínio. (Chartier, 1990:17)

Outro elemento que está presente na leitura do periódico é a observação do modo como o editor dispõe as informações nas seções do jornal e se estas, na forma como são constituídas, permitem ao leitor perceber a existência de um 'fio condutor' que interliga as seções e conduz a leitura do periódico. A percepção desse elemento revela as 'estratégias' do editor e deixa perceber qual a linha editorial pretendida sua proposta política, as práticas que pretende fomentar em seus leitores e quais aquelas que recomendam como próprias e as que elegem como não recomendadas.

Observada a composição gráfica dos jornais ${ }^{12}$ é possível considerar que esta permite ao leitor flutuar em um universo de informações passando de questões relativas à organização política do Território do Acre a temas que dão conta de atividades de cunho social.

\section{A VISIBILIDADE PRETENDIDA: INFORMAR E DIVULGAR}

O Jornal desempenha, no período que a análise recobre, importante papel no processo de organização dos serviços de educação no Território do Acre ao se constituir como um orientador dos procedimentos administrativos que eram adotados pelo governo como e, principalmente como um arauto do 'novo modelo de educação' que se estava a praticar país afora. Nesse sentido a publicação dos relatórios de Governo são fundamentais na direção de publicizar informações bem como constituir um grupo de leitores que acompanham, periodicamente, o desenrolar das ações de seus governantes, especialmente no que concerne as questões educacionais, objeto do estudo aqui apresentado.

Com esse diretriz é que o diretor departamental do Juruá, dirige-se aos leitores e lastreado pela determinação de que o jornal se constitui em 'órgão oficial' do governo e publica no ano de 1914 no jornal $O$ Cruzeiro do Sul ${ }^{13}$ o Relatório do Diretor do Departamento do Alto Juruá, Capitão Francisco Siqueira do Rego Barros, com a indicação de que este fora apresentado ao Ministro da Justiça e Negócios Interiores.

Rego Barros apresenta, em seu relatório a estatística escolar, com especial destaque para o número de escolas existentes e suas localizações, ao mesmo tempo em que relata a preocupação com a educação moral e cívica dos habitantes do Departamento Juruá e aponta a necessidade de criar um grupo escolar com capacidade para 250 alunos e a uma escola de ensino profissional, de sorte a garantir a educação das crianças e a formação profissional dos jovens e adultos.

Ao publicar o Relatório no jornal, o dirigente departamental não apenas dá ciência aos leitores da situação do departamento do Alto Juruá como também comunica a todos que este material fora remetido ao poder público Federal, dando assim a conhecer a relação entre o poder departamental e a esfera federal.

Importante registrar que o modo admitido para a publicação do Relatório é similar aquele utilizado para a publicação de "novelas" ${ }^{\text {, }}$, ou seja, em edições sequentes, sempre 
com a indicação de que continua no número seguinte do jornal. Desse modo, os leitores se colocam a 'espera' da conclusão que se anuncia no número anterior. Essa estratégia é repetida por todos os diretores dos Departamentos do território do Acre, o que permite aos leitores acompanharem as suas 'realizações' bem como as 'dificuldades' que são enfrentadas pela municipalidade.

Dentre as necessidades apontadas pelo diretor do departamento do Alto Juruá, no que importa a instrução pública está a indicação da necessidade de criação de uma escola profissional e de um curso secundário. De acordo com Rego Barros a justificativa para tal proposição está posta no fato de que,

Ressente-se esta cidade da falta de uma escola profissional onde as inúmeras crianças da cidade, filhos de proletários, se possam preparar para uma vida útil de trabalho. A instituição de um curso secundário é imprescindível a mocidade juruaense, pois que nem todos os chefes de família podem mandar aos estados, seus filhos afim de cursarem um curso secundário, sendo numerosas as crianças que já terminaram o curso primário e as que este ano concluirão esse curso. (cf. Cf. Jornal O Cruzeiro do Sul, organ oficial do Departamento do Alto Juruá, Território Federal do Acre, ano IX, n 325. (Coleção Museu da Borracha)

Dirigindo-se diretamente ao leitor, Rego Barros conclui suas informações relativamente a necessidade de criação de escola profissional e a o curso secundário, dando conta da insistência com a qual tem se dirigido ao governo federal, aguardando que este o habilite com os recursos necessários ao provimento de tais ações.

Nesse movimento os leitores têm a indicação não apenas das dificuldades enfrentadas pela municipalidade como e principalmente das intenções do Diretor do Departamento frente a tal situação, assim como se obtém a justificativa necessária a não realização de tais proposições: a falta de verbas.

A questão da instrução pública incomoda os governantes departamentais desde a instalação administrativa destes. No Relatório do antecessor de Rego Barros, Thaumaturgo Azevedo $^{15}$, relativo ao ano de 1905 , fica clara a preocupação situação que encontrara naquela localidade.

Em seu relatório, Thaumaturgo de Azevedo aborda questões relativas a criação de escolas, questões relacionadas à biblioteca, bem como a importância da instrução popular visando superar o analfabetismo.

Dirigindo-se ao Ministro do Interior, inicia o tópico referente a instrução pública informando que 'em todo o território do departamento, como já tive ensejo de scientificar a V. EX., nunca existiu a mais humilde aula de primeiras letras'. A partir dessa constatação passa Thaumaturgo de Azevedo passa apresentar as suas propostas para a instrução pública, sem deixar de demarcar que, ainda que esse estado de ignorância da população seja uma herança 'do deprimente atrazo que vem do Império', grande parte dos imigrantes que no Acre estão, são menores de 21 anos e 'atingiram a puberdade em plena Republica, que já completou 16 anos de existência'.

A crítica a situação anterior a República é imediatamente precedida de uma indicação da função da escola, quando este afirma que

Urge apertar os laços da nossa nacionalidade e nenhum meio há mais próprio para isso do que as escolas e a magistratura, apoiadas pela facilidade de comunicação e transporte. (cf. Relatório de Governo de Thaumaturgo de Azevedo, 1905. Departamento do Alto Juruáp. 17. (Museu da Borracha) 
A seguir Thaumaturgo de Azevedo passa a anunciar as possibilidades de 'apertar os laços da nossa nacionalidade' e propõe a Ministro do interior a criação de 'Escolas móveis, pelo methodo João de Deus' sob o argumento de que estas

Preparariam os discípulos agragados em cada barracão em ler, escrever e contar, em três a quatro meses. Com seis professores contratados em Portugal, que trabalhariam no verão nas escolas fixas e de inverno nas 'escolas ambulantes' sanhar-se-hia esta dificuldade. (cf. Relatório de Governo de Thaumaturgo de Azevedo, 1905. Departamento do Alto Juruáp. 19. (Museu da Borracha)

Concorde com as 'escolas móveis'16 se criariam 'bibliotecas ambulantes' que acompanhariam os professores na empreitada educacional, assim como se realizara nos 'Estados Unidos da América que devem as suas bibliotecas ambulantes (...) a maravilhosa assimilação dos colonos estrangeiros aos seus costumes.' Desse modo Thaumaturgo Azevedo definia o modo de 'apertar o laço' da pretendida nacionalidade a se instalada nos habitantes do departamento do Alto Juruá.

O traço reformador é mantido por todos os governantes do território do Acre, tanto no período departamental, quanto a partir de 1920, quando da unificação territorial.

Nos anos de 1924 e 1925, o então governador José Thomaz da Cunha Vasconcelos envia ao Ministro Affonso Penna Junior, ministro da justiça e publica tais documentos no jornal $\mathrm{O}$ Acre. No documento fica justificada que a deficiência do ensino em terras acreanas dá-se em função da falta de verbas para o ensino, a despeito de ações inovadoras e da determinação do povo acreano. Diz o governador em seu relatório que,

[...] a exígua verba que cabe a esta administração para o custeio dos serviços a seu cargo, não me permite tornar mais efficiente o ensino público. Para não fechar grande número desses estabelecimentos, em virtude da reducção que vem sofrendo a dotação orçamentária desde 1923, tive de, seguindo a pratica adoptada pelo meu antecessor, transferir o pagamento do professorado de boa parte das escolas para subconsignação Auxílio aos Municípios. (Relatório, THOMAZ DA CUNHA, 1924)

No ano de 1929 o Governador o território, sr Hugo Ribeiro Carneiro apresenta ao. Augusto de Vianna do Castello ministro da Justiça e Negócios Interiores o relatório de governo relativo ao período de janeiro de 1928 a outubro de 1929. De cordo com os dados estatísticos presentes no documento, existiam no Acre, naquele período um total de 105 estabelecimentos de ensino, divididos entre escolas territoriais e municipais estas estavas classificadas como grupos escolares, escolas primárias urbanas, escolas primárias rurais e escolas profissionais.

Os grupos escolares ficavam localizados nas sedes dos municípios. As escolas primárias urbanas, que poderiam ser diurnas ou noturnas, ficavam localizadas nas cidades ou vilas onde, além dos grupos escolares, se tornavam necessárias. As escolas primárias rurais, que também poderiam ser diurnas e noturnas, ficavam estabelecidas nos seringais ou outros núcleos de pequena população. As escolas profissionais, podendo ser urbanas ou rurais, ficavam conforme a sua denominação, situadas nas cidades ou vilas.

Relativamente as escolas rurais, Hugo Carneiro as apresenta como lugares em que a frequência dos alunos é difícil e a manutenção das mesmas torna-se, ao logo do ano impraticável. Como solução para este problema, Hugo Carneiro retoma a proposta 
apresentada anteriormente por Cunha Vasconcelos de criação de internatos agrícolas. Nesses estabelecimentos funcionariam cursos primários e profissionais. Esses cursos preparariam as crianças para quando saíssem desses internatos, estivessem prontas para entrarem na vida.

Em cada palhoça situada nos "varadouros", existe sempre de duas a seis creanças, na maioria analphabetas. Torna-se impossível a frequência destas creanças ás escolas que funccionam nas margens. Ellas não suportariam diariamente as viagens de ida e volta, principalmente na época invernosa, quando os "varadouros" estão cheios de lama. (Relatório, HUGO CARNEIRO, 1928/1929).

De um lado se observa a preocupação do governante com relação a profissionalização do que estão a morar nos seringais, de sorte a afasta-los da vida 'ingrata e cheia de dificuldades', de outro o desejo de criar uma escola preparatória para o magistério ganha força sob a justificativa de que

Não se póde conceber que uma administração desejosa de remodelar a instrucção pública, não envide esforços para a creação de uma escola onde se preparem aquelles que diffundirão os novos methodos de ensino pelos diversos pontos do Território substituindo os professores leigos que desconhecem mesmo os antigos systemas pedagógicos. (Relatório, HUGO CARNEIRO, 1928/1929).

Se num primeiro momento a idéia era a de instituição de uma base na qual se assentariam as ações governamentais, contribuindo com o desenvolvimento da República recém instituída, no outro as ações são dedicadas a aproximar o Acre das mais modernas condições que o País está a produzir, especialmente no que concerne a instrução pública. A modernidade é pretendida e requerida, sob pena de o território não se inserir no projeto de Nação que se está a instituir no Brasil republicano.

\section{A DIVULGAÇão DOS NOVOS RUMOS DA EDUCAÇ̃̃o NACIONAL: A FALA DO OUTRO}

A partir do ano de 1936 o jornal O Acre passa a publicar, para além das matérias relativas a administração local, documentos oriundos do governo federal, bem como abre um espaço para a publicação periódica de 'comunicados' da Associação Brasileira de Educação - $\mathrm{ABE}^{17}$.

Nesse momento a Associação Brasileira de Educação - ABE desempenha importante papel no que concerne a divulgação de seu projeto de defesa da escola brasileira.

Os Comunicados da $\mathrm{ABE}$ são publicados com regularidade e apontam a importância que a imprensa tem nesse processo de divulgação do novo ao mesmo tempo em que revela a posição da Associação Brasileira de Educação no momento em que esta encaminha ao poder público, sugestões de procedimentos com vistas a organização da educação nacional e, ao mesmo tempo indica o compromisso do governo federal com a educação nacional, diferentemente do que se observara nos primeiros anos da República.

Noutra direção pode-se observar a defesa da ABE relativamente a função da propaganda e necessária construção de uma 'opinião nacional' em matéria de educação e para isso a Associação não dirige seus esforços através das

Advertências de seus técnicos, na palavra de seus dirigentes, nos congressos, nas exposições pedagógicas, nos cursos de extensão e de 
auspícios ou como fruto de suas iniciativas diretas. (cf. ABE - Instruindo e Divulgando O Acre, $n^{\circ} 312,1936$ - Acervo Museu da Borracha)

No Comunicado denominado Instruindo e Divulgando, a $\mathrm{ABE}$ alerta ao público leitor que,

Não basta, porém, o interesse das metrópoles para o êxito da campanha empreendida. Torna-se necessária a interiorização da propaganda para que se atinja o âmago da nacionalidade, familiarizando o povo das cidades e vilas do "hinlerland" com o conceito proeminente da educação na prosperidade das nações e com o desvelo que lhe tributam, conscientes dessa verdade, os países líderes do mundo.

É no intuito de assegurar a plena influência dessa obra divulgadora que a Associação Brasileira de Educação empreende a extensão a todos os Estados e Municípios afiliados em seu programa de ação social". (cf. ABE - Instruindo e Divulgando O Acre, n 312, 1936 - Acervo Museu da Borracha)

O modo como a opinião pública se poderia fazer presente nesse debate também é anunciado. Nesse momento a Associação deixa absolutamente claro qual o papel da imprensa na formação de uma mentalidade esclarecida, que se transformará no solo fértil onde se depositarão as orientações para a educação nacional. Diz o Comunicado da ABE que,

O generoso concurso da imprensa para a vulgarização, em breves comunicados, faz realizações mais importantes que assinalam o progresso do movimento educativo, dentro e fora do País, não visa também outro objetivo. Só por esse meio será possível manter o contato direto e permanente do povo com uma atividade que, para suscitar entusiasmos e tornar-se alvo de gerais simpatias precisa empolgar, pelas constantes referências do noticiário a atenção do público leitor, até que fixada a noção de sua relevância no subconsciente das populações, venham estas a compreender, educando-se os direitos e deveres que lhe competem em face a democracia. (cf. Museu da Borracha, O Acre, n. 312 de 19/01/1936)

A temática abordada pela Associação Brasileira de Educação, qual seja, a utilização da imprensa na formação de uma 'mentalidade esclarecida' em matéria de educação não é nova. Esse dispositivo é fartamente anunciado num comunicado ${ }^{18}$ da Diretoria Geral de Estatística e Divulgação do Ministério de Educação e Saúde Pública através de um comunicado intitulado Escolar. Imprensa e Vida Escolar, publicado no jornal $O$ Acre, no ano de 1933, ocasião em que se explicita o papel da imprensa oficial na divulgação dos ideais nacionais relativamente a educação.

O Comunicado se inicia considerando que é necessário a 'preparação do meio' para que as grandes realizações de efetivem, e conclui que sem que esta preparação se dê as tentativas rumo ao progresso social 'nunca passarão de tentativas condenadas ao fracasso'.

Onde falham as condições de receptividade da massa ao povo, relativamente as inovações edificantes, conducentes a orientar para os melhores rumos a evolução das comunidades civilizadas, os programas de aperfeiçoamento, por melhores que sejam as intenções de seus autores, não logram vencer as barreiras levantadas pela indiferença, apatia e mesmo aversão das populações mal instruídas e aferradas a rotina. As próprias leis Progressistas resultam inoperantes pela falta de apoio da opinião coletiva e quanto mais adiantadas no seu pensamento, tanto 
menos eficientes se revelam pela falta de cooperação Pública, falta sempre emergente na incompreensão generalizada doa altos desígnios do legislador. (A Acre, $\mathrm{n}^{\circ}$ 182, 1933 - Acervo Museu da Borracha)

Observe-se o descompasso sugerido pela Diretoria Geral de Estatística e Divulgação do Ministério de Educação e Saúde Pública entre a ação do legislador e a opinião pública é determinado como a grande causa do mau funcionamento das instituições públicas. A idéia é a de criar uma 'mentalidade pública' na defesa da instrução e da conseqüente modernização do país. A relação entre o povo e os legisladores é uma necessidade, de sorte que estes últimos sejam provocados a realizar a obra que o País carecia, garantindo com isso o 'vigor da república', vigor este que não se efetivaria se a população não compreendesse a relevância da educação e dos seus métodos.

O perfeito conhecimento do assunto despertaria entusiasmo e integraria a nação nos propósitos das administrações regionais e federal. (A Acre, $\mathrm{n}^{\circ}$ 182, 1933 - Acervo Museu da Borracha)

A integração pretendida é anunciada a partir da idéia de que 'urge preparar a consciência nacional por meio da publicidade' e a imprensa é apontada como o 'mais poderoso instrumento de transformação da mentalidade predominante no País', e, se bem utilizado em muito concorreria para modificar a 'atitude do povo em face a questão educacional'. Conviria, a partir dessa proposição publicizar as questões relativas a educação, não só a partir de

Simples afirmações sobre a relevância da instrução no desenvolvimento da nacionalidade, mas de informações positivas sobre a vida escolar tal como se processa no país e no estrangeiro de modo a sugerir, ou patentear, pelo conhecimento do problema, o que já tem sido feito e o que ainda é preciso fazer, as perspectivas a alcançar e as falhas a corrigir para a nossa útil progressão na esteira dos povos mais avançados em matéria de ensino. (A Acre, $n^{\circ}$ 182, 1933 - Acervo Museu da Borracha)

A indicação é dirigida ao poder público, sugerindo a estes que criem 'folhas oficiais' nos estados da federação. Na perspectiva do governo federal,

A circulação obrigatória das folhas oficiais na numerosa classe do funcionalismo muito concorreria para habilitar uma parte da população com a exata consciência da extensão e da complexidade do esforço a desenvolver em prol da formação intelectual da juventude e, desse conhecimento resultaria um poderoso incremento das hostes que militam pela boa causa. Todos os brasileiros que sabem ler e escrever deveriam ser, na fase atual de nossa civilização, educadores e mais ainda evangelizadores empenhados com ardor no serviço da educação nacional. (A Acre, $n^{\circ} 182,1933$ - Acervo Museu da Borracha)

Se no ano de 1908 no jornal O Alto Purus anuncia que se constitui em órgão oficial e se coloca como 'absolutamente alheio a política' e define sua finalidade como aquela que se dirige ao engrandecimento da futura nação brasileira, e, nessa direção, a exemplo dos demais periódicos publicados pelos departamentos administrativos do Acre e pelo governo territorial, é mantida uma intensa publicação de atos e fatos da administração departamental e territorial, a partir desse instante a indicação, proveniente do governo federal ratifica a ação já praticada em terras acreanas.

Ao utilizar-se do jornal para 'divulgar' as ações de governo e 'instruir' a população e os funcionários públicos nos procedimentos adotados pela administração pública com vistas ao desenvolvimento local e a integração do território acreano na Nação brasileira, 
não apenas através de sua determinação administrativa e geográfica e, principalmente porque aqui se desenvolviam ações de par com aquelas desenvolvidas nos grandes centros do País, o governo territorial enceta uma política de divulgação de suas ações, ao mesmo tempo em que faz publicar comunicados oriundos dos órgãos dos ministérios federais, da Associação Brasileira de Educação - ABE forja nos leitores uma percepção de a educação acreana enfrenta problemas muito próximos daqueles enfrentados por outros estados brasileiros.

\section{BIBLIOGRAFIA}

\section{LIVROS}

1. ASSOCIAÇÃO BRASILEIRA DE EDUCAÇÃO (1934). O problema educacional e a Constituição. São Paulo: Companhia Editora Nacional.

2. BOMENY, Helena M. B. (1999). Três decretos e um ministério: a propósito da educação no Estado Novo. In PANDOLFI, Dulce Chaves, org. Repensando o Estado Novo. Rio de Janeiro: Ed. da FGV.

3. BRASIL. Decreto $\mathrm{n}^{\circ} 19.560$, de 5 de janeiro de 1931 (Regulamenta o funcionamento do Ministério da Educação e Saúde Pública).

4. CAPELATO, Maria Helena (1989). Os Arautos do Liberalismo: imprensa paulista 1920-1945. São Paulo, Brasiliense,.

5. CAPELATO, Maria Helena (1998). Imprensa e História do Brasil: imprensa oficial e imprensa contestadora, o jornal como documento, o papel do jornal na história. São Paulo, Contexto, 2. ed..

6. CAPELATO, Maria Helena R. Imprensa e História do Brasil. Contexto/EDUSP, São Paulo, 1994.

7. CARVAlHO, Marta Maria Chagas de (1999). O território do consenso e a demarcação do perigo: política e memória no debate educacional nos anos 30. In FREITAS, Marcos Cezar, org. Memória intelectual brasileira. Bragança Paulista (SP): Edusf (Editora da Universidade São Francisco).

8. CASTRO, Maria Ceres Pimenta Spinola. [et. al]. Folhas do tempo: imprensa e cotidiano em Belo Horizonte 1895-1926. UFMG, Associação Mineira e Imprensa; Prfeitura Municipal de belo horizonte, BH, 1997.

9. CATANI, Denice Barbara \& BASTOS, Maria Helena Câmara, orgs. (1997). Educação em revista: a imprensa periódica e a história da educação. São Paulo: Escrituras.

10. CERTEAU, Michel de. (1994) A invenção do cotidiano. Petrópolis: Vozes,

11. CHARTIER, Roger. (1990) História Cultural: entre práticas e representações. Difel, Lisboa,. (Coleção Memória e Sociedade).

12. CHARTIER, Roger. A ordem dos Livros: leitores, autores e bibliotecas na Europa entre os séculos XIV e XVIII. Trad. Mary Del Priore - Brasilia : Editora Universidade de Brasília, $2^{a}$ ed., 1998. 
13. DANTAS, Andréa Maria Lopes. A urdidura da Revista Brasileira de Estudos Pedagógicos nos bastidores do Instituto Nacional de Estudos Pedagógicos: a gestão Lourenço Filho (1938-1946), PUC/SP, 2001. Tese de Doutoramento.

14. FOUCAULT, Michel. O que é um autor? Trad. Antonio Fernando Cascais e Eduardo Cordeiro. Ed. Garrido \& Lino, $3^{\text {a }}$ ed. Vega: Passagens, 1997.

15. KARYDIS, Penélope et al. (1981). La presse d'éducation et d'enseignement (XVIIIéme siècle-1940). Tome I, A-C. Paris:, INRP/Editions du CNRS.

16. LOPES, Eliane Marta Teixeira. (et. al). 500 anos de educação no Brasil. BH: Autêntica, 2002. $2^{\mathrm{a}}$ ed.

17. MINISTÉRIO DA EDUCAÇÃO E SAÚDE [1937]. Conselho Nacional de Educação: sessões da primeira reunião de 1937. Vol. I. Rio de Janeiro: Imprensa Nacional - Indústria do Jornal..

18. NUNES, Clarice e CARVALHO, M. M. Chagas de. Historiografia da Educação e Fontes. Caxambu - MG, Anped, 1992.

19. PECAUT, Daniel (1990). Os intelectuais e a política no Brasil: entre o povo e a nação. São Paulo: Ática.

20. WARDE, Mirian (org). Temas de História da Educação. Contemporaneidade e Educação: revista semestral de Ciências Sociais e Educação. IEC, ano V, n ${ }^{\circ} 06$ $1^{\circ}$ semestre,. Rio de Janeiro 2000.

\section{JORNAIS - ACERVO MUSEU dA BORRACHA}

1. O Alto Purus, 24 de fevereiro de 1908.

2. Alto Purus, 25 de fevereiro de 1911.

3. O Cruzeiro do Sul, de março de 1905.

4. O Cruzeiro do Sul, , $\mathrm{n}^{\circ} 325,1913$

5. O Cruzeiro do Sul, n. 449 de 24/10/1915.

6. O Acre, 1924 a 1936.

\section{RELATÓRIOS DE GOVERNO}

7. Relatório de Governo de Thaumaturgo de Azevedo, 1905. Departamento do Alto Juruá (Acervo Museu da Borracha)

8. Relatório apresentado ao Exm. Sr. Ministro da Justiça e Negócios Interiores, relativo ao $2^{\circ}$ semestre de 1913 pelo Capitão Francisco Siqueira Rego Barros, Prefeito do Departamento do Alto Juruá,. (Acervo Museu da Borracha)

9. Relatório Cunha Vasconcelos, 1925 - Governo do Território do Acre (Acervo Museu da Borracha)

10. Relatório apresentado ao Exmo. Sr. Dr. Augusto de Vianna do Castello ministro da justiça e negócios interiores pelo Dr. Hugo Ribeiro Carneiro governador do Território do Acre - relativo ao período de janeiro do anno de 1928 a outubro de 1929. (Acervo Museu da Borracha)

Notas

\footnotetext{
${ }^{1} \mathrm{O}$ termo autonomista é utilizado para definir o grupo de intelectuais que nos anos de 1950 se organizam em torno da idéia da independência do território do Acre, através da elevação deste a categoria de Estado da
} 
Federação Brasileira. Dentre as várias ações desses intelectuais está a publicação de um periódico de circulação em todo o território acreano difundindo os ideais autonomistas.

${ }^{2}$ No jornal $O$ Rebate, publicado na cidade de Cruzeiro do Sul existe uma lista com o nome e a periodicidade dos impressos que circularam no território do Acre de 1902 até a década de 1960. (Acervo Particular Gizalda Mariano)

${ }^{3}$ O Território do acre foi anexado ao Brasil no ano de 1904 através do decreto Presidencial n. 5.188. Ainda que administrativamente estivesse ligado a uma delegacia executiva em Manaus, por ordenação presidencial o território foi dividido em três Departamentos que agregavam seringais e povoados já constituídos desde o final do séc. XIX, respectivamente, Alto-Acre, Alto-Purus e Alto Juruá e Tarauacá. No ano de 1912, através do Decreto-Lei n. 9.831, o Departamento do Alto-Juruá foi desmembrado, dando origem ao Departamento do Alto-Juruá e Departamento de Tarauacá. Cada Departamento era administrado por um Prefeito nomeado pelo Presidente da República

${ }^{4}$ Esses periódicos são encontrados no Museu da Borracha, sediado na cidade de Rio Branco, Acre e estão disponíveis para consulta.

${ }^{5}$ Cf. Nadjanayra Neri de Moura. O JORNAL ALTO PURUS: Uma análise de algumas notícias e sua relação com a educação no Departamento do Alto Purus (1908 - 1914). 2003. TCC/Curso de Pedagogia. Orientado por Andréa Maria Lopes Dantas

${ }^{6}$ Os elementos aqui apresentados constam da estrutura do jornal O Acre. Cf. O Acre, 1935.

${ }^{7}$ O Acre permanece na condição de Território Federal de 1920 a 1962, quando passa a condição de Estado.

${ }^{8}$ No ano de 1918 o jornal O Cruzeiro do Sul deixa de ser editado e no ano de 1918 o jornal Alto Purus passa a se chamar Gazeta do Purus e, ainda que guarde traços das publicações anteriores e publique matérias relativas ao poder municipal e federal, não se constitui mais em órgão oficial do município de Sena Madureira, sede do antigo Departamento do Alto Purus e encerra a sua publicação em 1924.

${ }^{9}$ A pesquisa não identificou jornais ou outro tipo de publicação semelhante aquelas que se constituíam em 'órgãos de imprensa dos departamentos administrativos', relativamente aos municípios do território unificado.

${ }^{10}$ O Departamento de Educação e Cultura é instalado em 1939 através do Decreto Territorial n. 19 que reorganiza a Diretoria de Educação, Estatística e Biblioteca, órgão que coordenava os serviços de educação em todo o território acreano. (cf. Museu da Borracha, O Acre, de 12/02/1939)

${ }^{11}$ Além dos estudos de Roger Chartier,(1990) serão fundamentais para a pesquisa as análises de Michel de Certeau (1997), Penélope Karydis (1981), Daniel Pecaut (1994) Marta Maria Chagas de Carvalho (2000), Denice Bárbara Catani (1997).

${ }^{12}$ No que importa a organização tipográfica e finalidade dos periódicos é possível perceber que estes tinham uma estrutura comum, sendo organizados em cinco colunas, em alguns casos se apresentam seis colunas dispostas em oito páginas. O nome do jornal aparece centralizado na primeira página e, logo abaixo está informado que este se constitui em um órgão do Departamento Territorial. Seguem-se as informações referentes ao ano, número da publicação e a data da mesma. As seções que compõem o jornal são separadas por linha final ou tracejadas. A numeração é posta a direita das páginas e sempre em negrito

${ }^{13}$ Cf. Jornal O Cruzeiro do Sul, organ oficial do Departamento do Alto Juruá, Território Federal do Acre, ano IX, no 325. (Coleção Museu da Borracha)

${ }^{14} \mathrm{O}$ formato de publicação tipo 'folhetim' é utilizado por todos os editores dos jornais publicados no território acreano e não apenas relativamente as matérias de cunho governamental. Ainda que não seja objeto desse estudo é possível localizar, no jornal O Cruzeiro do Sul, nos anos de 1920, a publicação de textos literários nesse formato.

15 Relatório de Governo de Thaumaturgo de Azevedo, 1905. Departamento do Alto Juruá. (Museu da Borracha)

${ }^{16}$ Não foi possível determinar a aplicação do método João de Deus em escolas acreanas. No entanto, a criação das escolas móveis se tornou uma realidade, nominadas como 'escolas ambulantes' e constando da estatística oficial, devidamente publicada nos jornais do território.

${ }^{17}$ Foi possível localizar oito Comunicados da ABE publicado no jornal O Acre nos anos de 1931 e 1936 . São eles: 1931, 4ª Conferência Nacional de Educação (24/01); 1936 - Instruindo e Divulgando; Congressos Internacionais; O Plano Nacional de Educação; A A.B.E e a Cooperação Interadministrativa; Custo Médio de um Aluno; O Ensino Normal Rural; A Ortografia Simplificada na Educação Primária; Mapas Municipais.

${ }^{18}$ A Imprensa e a Vida escolar. O Acre, no 182, 1933 - Acervo Museu da Borracha.

Recebido em: $\quad 08 / 07 / 2011$

Aprovado em: $\quad 25 / 07 / 2011$ 